\title{
METODOLOGIA PARA DETERMINAÇÃO DA QUALIDADE AMBIENTAL URBANA
}

\author{
João Carlos Nucci *
}

\begin{abstract}
RESUMO
Fundamentado no "Planejamento da Paisagem" sugere-se uma metodologia para a avaliação da qualidade do ambiente urbano, utilizando-se como exemplo o distrito de Santa Cecília no Município de São Paulo. Uso do solo, poluição, espaços livres, verticalidade das edificações, enchente, densidade populacional e cobertura vegetal, são os atributos analisados e espacializados em escalas que variam entre 1:2.000 e 1:10.000. A análise sistêmica dessas variáveis fornece a carta de Qualidade Ambiental.
\end{abstract}

\section{INTRODUÇÃO}

Desde a década de 70 as propostas de planejamento urbano para o Município de São Paulo (MSP) colocam o adensamento como resposta às demandas sociais. O adensamento proposto, que significa uma intensificação do uso e ocupação do solo, aparece vinculado à disponibilidade de infraestrutura e às condições do meio físico. Então, a área que se apresentasse com uma infra-estrutura subutilizada e sem impedimentos do meio físico seria considerada como passível de adensamento, entendendo-se como infra-estrutura as redes de água, luz, esgoto, telefone e gás encanado. Os levantamentos das condições do MSP que justificam o adensamento de certas áreas são realizados, pelas diferentes gestões, em escalas espaciais menores do que 1:50.000. O diagnóstico e o prognóstico realizados em escalas espaciais menores do que 1:50.000 é uma metodologia escolhida na elaboração das propostas de planos diretores que devem conter, em um primeiro momento, diretrizes gerais, e que os problemas específicos devem ser posteriormente analisados em uma escala local. Constata-se, também, que não se encontram normas, critérios e padrões suficientes para se assegurar um "(...) meio ambiente humanizado, sadio e ecologicamente equilibrado", como propõe, por exemplo, a Lei Orgânica do MSP de 1990, e que, portanto, os impedimentos do meio físico, ou ambiental, não são considerados no momento das decisões.

Entendendo-se que a sociedade humana depende, para seu bem-estar, da consideração não só dos parâmetros éticos e sociais, mas também dos fatores ambientais, apresenta-se, nesse trabalho, uma metodologia que leva em consideração os atributos ambientais diagnosticados e espacializados de forma integrada e em uma escala espacial local (entre 1:2.000 e 1:10.000). Propõe-se, portanto, uma forma de diagnosticar o outro lado do problema, o lado da "oferta", ou

(*) Doutor pelo Departamento de Geografia da Faculdade de Filosofia, Letras e Ciências Humanas/USP. 
seja, da capacidade que o ambiente tem para acolher os diferentes usos do solo de acordo com a qualidade ambiental que apresenta, já que, o lado da "demanda", é bastante conhecido e mais considerado no planejamento urbano.

Essa proposta metodológica foi executada no diagnóstico ambiental do distrito de Santa Cecília (MSP) por Nucci (1996); entretanto, a metodologia aqui considerada poderá ser aplicada para a totalidade do Município de São Paulo, bem como outras áreas urbanizadas.

Essa metodologia tem como base geral o "Planejamento da Paisagem"; que pode ser entendido como uma contribuição ecológica e de design para o planejamento do espaço, onde se procura uma regulamentação dos usos do solo e dos recursos ambientais, salvaguardando a capacidade dos ecossistemas e o potencial recreativo da paisagem, retirando-se o máximo proveito do que a vegetação pode fornecer para a melhoria da qualidade ambiental.

Monteiro (1987) coloca que "Executar um trabalho de espacialização da qualidade ambiental constitui um verdadeiro desafio, visto que não existe uma receita técnica calcada numa concepção teórico-metodológica pronta". Sendo assim, este trabalho vem colaborar para aumentar o escasso rol de possibilidades metodológicas para a abordagem do meio ambiente urbanizado e, consciente da pretensiosa atitude, contribuir para que a Geografia, como uma ciência de síntese pluridisciplinar, possa cada vez mais se mostrar como fundamental em qualquer estudo do meio ambiente.

\section{O PLANEJAMENTO DA PAISAGEM}

Quando se pensa em planejamento do espaço, está se pensando no "todo", nos aspectos sociais, econômicos e naturais, mas faz-se necessária uma divisão desse espaço para um melhor entendimento, pois as metodologias de estudo até agora conhecidas ainda não foram capazes de estudar o espaço levando em consideração todas as suas variáveis e inter-relações. Portanto, o que atualmente tem acontecido são estudos em esferas diferentes do planejamento com uma posterior tentativa de sínteses parciais, dentro de cada linha de estudo, e depois uma síntese mais globalizante com o intuito de propor medidas de planejamento do espaço. Entretanto, no momento de se fazer essa síntese final, nem todos os aspectos estudados são considerados na tomada de decisões. Tenta-se, assim, uma mudança do pensamento que até hoje coordena a forma de planejamento do espaço: “Na sociedade burguesa, preocupações econômicas constituem o tema principal da investigação social; todas as outras considerações humanas são secundárias" (Lefebvre, 1969), como também as existenciais. Sendo assim, o planejamento acaba ficando nas mãos daqueles que "(...) têm ignorado que a sociedade humana depende do meio ambiente biofísico para sua sobrevivência" (Douglas, 1983). Rocha (1991) coloca que "Na realidade, o comportamento humano é regido não só por parâmetros éticos e sociais, mas também por fatores ambientais. Ora, em um ambiente urbano que constitui o verdadeiro habitat e'nicho' do ser humano, obviamente, ele deve (ou deveria ser) o ponto central de referência quando da tomada de qualquer decisão pela autoridade constituída, ou no nível da própria cidadania."

Muitas vezes também o planejamento é baseado somente em medidas de ordem tecnológica, sem se importar com o ordenamento do ambiente. "As cidades crescem bem acima de sua capacidade natural de suporte, graças ao uso da tecnologia. As grandes metrópoles, portanto, são 
muito dependentes do aparatus tecnológico, o que significa que uma falha mecânica pode trazer sérias repercussões ao ecossistema urbano" (Marcus e Detwyler, 1972). O termo "capacidade natural de suporte" está relacionado com os limites de ocupação do território, e ainda requer mais estudo, para que se possa alcançar uma melhor definição. ${ }^{1}$

Apesar dos trabalhos na área ambiental até agora elaborados colaborarem para a formação de uma base conceitual, sente-se a falta desses estudos na paisagem urbana em escalas maiores, e o que se encontra atualmente mais próximo da nossa preocupação referente aos estudos urbanos são os trabalhos realizados na Alemanha sobre Planejamento da Paisagem.

Um trabalho sobre a Conferência Internacional realizada em 1990 sobre Planejamento da Paisagem na Alemanha, "A contribuição do Planejamento da Paisagem para a proteção ambiental" (Landschaftsplanung als Instrument umfassender Umweltvorsoge), por Dr. Hans Hiemstedt e Evelyn Gustedt, que se resume a seguir, nos dá uma noção sobre essa forma de planejamento.

O Planejamento da Paisagem tem suas raízes históricas no "embelezamento da paisagem" que dura até os primeiros anos do século XIX. No início da Revolução Industrial o Planejamento da Paisagem começa a se preocupar com o desenvolvimento caótico das cidades e com o crescimento da destruição da natureza, tentanto propor melhorias através do planejamento dos espaços livres (Grünplanung). Em meados do século XX, o conceito relacionado com o desenvolvimento espacial da paisagem passa a considerar, além das questões estéticas, as inter-relações ecológicas entre os elementos do ambiente. Essa situação levou a uma campanha em meados da década de 60 para se definir o Planejamento da Paisagem como "contribuição ecológica e de de- sign para o planejamento do espaço", com a definição de três áreas de concentração: Manejo da Paisagem (Landschaftspflege) na zona rural, Planejamento de Espaços Livres (Grünordnung) em zona urbana e Proteção da Natureza (Naturschutz). Assim, começam a se consolidar os programas de Planejamento da Paisagem nas universidades, e os trabalhos científicos nessa área tomam uma direção nos próximos anos. A partir do "Ato Federal de Proteção da Natureza" (Bundesnaturschutzgesetz), que foi aprovado em 20.12.76 e revisado em 10.12.86, e os Atos Estaduais de Proteção da Natureza, que regulamentam as leis federais, os objetivos do Planejamento da Paisagem se solidificam como os de proteção e manejo da natureza e da paisagem em áreas urbanizadas ou não. O Planejamento da Paisagem seria um instrumento de proteção e desenvolvimento da natureza com o objetivo de salvaguardar a capacidade dos ecossistemas e o potencial recreativo da paisagem como partes fundamentais para a vida humana. Portanto, as metas do Planejamento da Paisagem seriam:

- salvaguardar a diversidade animal e vegetal e suas biocenoses através do desenvolvimento de uma rede interligada de áreas protegidas, renaturalização de cursos d'água, revegetação, reflorestamento, etc. Nesse item a Cartografia de Biótopos é a parte mais importante nesta tarefa de proteção de espécies e biótopos.

- salvaguardar as paisagens, seus elementos e os espaços livres em áreas urbanas para fornecer a oportunidade de contato contemplativo e

(1) O Prof. Felisberto Cavalheiro, do Departamento de Geografia da USP, coloca que primeiro deve-se tirar partido do que a natureza pode oferecer no tocante à auto-regulação, para então estudar quais devem ser as tecnologias mais compatíveis a serem utilizadas. 
recreativo na natureza em contraste com as atividades recreativas comerciais. As áreas precisam ser designadas e protegidas do impacto visual, ruídos e poluição.

- salvaguardar o solo, a água e o clima através da regulamentação de seus usos e regeneração dos recursos. Controle do runoff, da permeabilidade dos solos, dos aquííferos, da poluição. Utilização da vegetação como forma de controle.

A regulamentação e regeneração das funções, dos tipos e da intensidade dos usos do solo devem estar condicionadas ao Planejamento da Paisagem, utilizando-se dos efeitos positivos que a vegetação pode fornecer. Portanto, o Planejamento da Paisagem está diretamente relacionado com o planejamento do espaço em diferentes escalas, sempre levando-se em consideração a proteção da natureza e o manejo da paisagem, trazendo para o planejamento uma forte orientação ecológica e visão interdisciplinar, contribuindo também com os outros setores do planejamento (Tabela 1).

TABELA 1 - Níveis de planejamento na Alemanha (modificada por Nucci, 1996).

\begin{tabular}{|l|c|c|c|}
\hline $\begin{array}{l}\text { PLANNING } \\
\text { LEVELS }\end{array}$ & $\begin{array}{c}\text { COMPREHENSIVE } \\
\text { PLANNING }\end{array}$ & $\begin{array}{c}\text { LANDSCAPE } \\
\text { PLANNING }\end{array}$ & \\
\hline FEDERAL & FEDERAL & & \\
& DEVELOPMENT & & \\
\hline STATE & STATE LAND & & $1: 1.000 .000$ \\
& DEVELOPMENT & A \\
& PROGRAMS/PLAN & PROGRAM & $1: 500.000$ \\
\hline $\begin{array}{l}\text { Region: } \\
\text { ADMINISTRATIVE }\end{array}$ & REGIONAL PLAN & REGIONAL & $1: 50.000$ \\
DISTRICT & & LANDSCAPE PLAN & A \\
COUNTY & & & $1: 25.000$ \\
\hline COMMUNIY/ & LAND USE/ & LOCAL & $1: 10.000 \mathrm{~A} 1: 5.000$ \\
TOWN & MASTER PLAN & LANDSCAPE PLAN & \\
& & URBAN OPEN & $1: 1.000$ \\
\hline SITE & & SPACE PLAN & \\
\hline
\end{tabular}

Atualmente, o que não permite uma maior eficiência da política ambiental é a falta de critérios necessários para a avaliação da qualidade ambiental.

Alguns resultados dentro dessa linha metodológica são divulgados dentro das disciplinas ministradas pelo Prof. Dr. Felisberto Cavalheiro do Departamento de Geografia da USP.
Uma transparência organizada por F. Cavalheiro, M. C. de Oliveira e P. C. D. Del Picchia, em 1987; coloca as condições básicas a se considerar em Planejamento da Paisagem:

1) Respeito ao potencial do meio ambiente.

2) Valorização das relações da natureza. 
3) Atingir uma melhor integração homem/natureza.

4) Respeito às condições culturais (sociais, econômicas, etnográficas, etc.).

5) Participação da comunidade nas decisões.

6) O planejador deve oferecer as melhores opções de planejamento.

7) Deve-se seguir uma ética em relação à natureza, ao projeto, como profissional em relação às comunidades envolvidas.

8) O planejamento é interdisciplinar.

9) Deve-se combater o corporativismo.

10) O projeto deve ser aberto e sujeito a contínuo replanejamento.

Sabe-se que, até 1990, mais de 150 cidades alemãs já tinham realizado seus diagnósticos e cartografado biótopos urbanos, com vistas à avaliação da qualidade ambiental e proposições para o ordenamento do meio físico (Sukopp, 1990 in Cavalheiro e Del Picchia, 1992); no Brasil, ainda são poucos os estudos de Planejamento da Paisagem que se propõem a espacializar de forma integrada os componentes do ambiente com o objetivo de diagnosticar e propor melhorias e, quando se trata da paisagem urbanizada, os estudos são quase inexistentes principalmente nas escalas maiores que 1:10.000.

\section{PROPOSTA METODOLÓGICA}

Dentro da metodologia do Planejamento da Paisagem a principal ferramenta é a espacialização dos atributos ambientais para posterior análise sistêmica. A preocupação é, portanto, aglutinar o máximo de dados cartografáveis da área em estudo para posterior cruzamento e elaboração de um diagnóstico ambiental espacializado. Pretende-se, portanto, chegar a uma síntese, o que requer alguns cuidados, segundo Martinelli (1994): "Na representação de síntese não podemos mais contar com a participação dos elementos considerados no nível analítico, e sim a fusão deles em conjuntos espaciais característicos. Isto significa que os mapas ambientais deverão ressaltar agrupamentos de lugares definidos por agrupamentos de atributos ou variáveis".

Dentro do nível analítico, serão espacializadas e analisadas as seguintes variáveis ambientais: uso do solo, poluição, verticalidade das edificações, densidade populacional, déficit de espaços livres públicos, deserto florístico e enchentes. A partir dessas cartas, chega-se a uma síntese, ou seja, a carta de Qualidade Ambiental.

Devido à falta de dados e de critérios amplamente aceitos, necessários para a avaliação da qualidade ambiental, pode-se optar por trabalhar com inferências baseadas em diferentes autores. Para evitar as discussões sobre aspectos subjetivos que podem impedir a aplicação dessa metodologia, sugere-se o devido cuidado de se considerar limites não muito restritivos. Sendo assim, os parâmetros apresentados, discutidos e eleitos neste trabalho não devem ser considerados como ideais autoritariamente impostos pelo pesquisador, mas podem servir como ponto de partida para discussão e posterior eleição pela comunidade dos critérios por ela considerados "ideais".

\subsection{Escala Espacial}

Em primeiro lugar, deve-se entender que limites de ordem prática precisam ser colocados e, talvez, o primeiro e principal limite é a escala espacial de abordagem que, em um trabalho de geografia física voltado para o ordenamento ambiental, define praticamente todo o procedimento que o pesquisador irá desenvolver ao longo da pesquisa. 
Sobre a questão da escala, Bertin (1968) afirma que "Toda exposição, seja oral, escrita ou gráfica, parte de uma informação complexa e tem o propósito de tornar-se compreensível através de uma redução simplificada (...) para 'representar' a realidade, se não recorrêssemos à noção de escala, seríamos pura e simplesmante afogados pela corrente de percepções que nos assaltam ininterruptamente (...) a escala aparece desde então como um filtro que empobrece a realidade mas que preserva aquilo que é pertinente em relação a uma dada intenção".

Se a Geografia não pretende uma descrição separada dos elementos da realidade, mas sim uma passagem dessa heterogeneidade para uma homogeneidade, deve-se tomar cuidado na escolha da escala que será utilizada para a coleta dos dados para posterior generalização. Uma escolha errada da escala de trabalho pode derrubar totalmente a tese de um pesquisador, porque a variação das escalas pode modificar a relação entre o homogêneo e o heterogêneo. Não basta o pesquisador se justificar dizendo que a escala adotada foi a de 1:50.000, e não 1:5.000. Então, é importante escolher uma escala ideal, não se esquecendo de verificar as escalas adjacentes a ela.

$\mathrm{Na}$ escolha da escala espacial deve-se levar em consideração o tamanho da área de estudo e o nível de percepção física que se pretende ter.

No caso do Município de São Paulo, devem ser considerados os limites dos distritos, segundo a Lei municipal n 11.220 de 20/05/92 (Fig. 1), pois, segundo a Lei Orgânica do MSP de 1990, os distritos podem ser considerados como "unidades de planejamento": "Art. 157 - O Município instituirá a divisão geográfica de sua área em Distritos, a serem adotados como base para a organização da prestação dos diferentes serviços públicos" (PMSP, 1990).

O nível de percepção pretendido deve ser o do lote, pois acredita-se que a cidade como um todo é a conseqüência da utilização que cada cidadão faz de seu lote. Essas escolhas remetem o pesquisador a uma escala espacial de abordagem da ordem de 1:2.000, e isto significaria trabalhar, para cada distrito, com várias cartas cadastrais de $53 \times 60 \mathrm{~cm}$, aumentando a dificuldade de realização do trabalho.

Sendo assim, pode-se optar, no trabalho de campo, pela coleta de dados na escala 1:2.000, mas somente do que pode ser visualisado pela calçada, ou seja, não é necessário entrar em cada lote para fazer o levantamento de seu uso total. Levantam-se os usos de cada lote como também o número de pavimentos, na escala 1:2.000. ${ }^{2}$

Nucci e Cavalheiro (no prelo), apesar das críticas à inexequuibilidade desse levantamento para todo o MSP, provaram que esse procedimento é possível e que 100 pessoas conseguiriam levantar o uso do solo e a verticalidade dos lotes do MSP em, no máximo, 181 dias de 6 horas de trabalho, ou em outros termos, 108.600 horas por pessoa.

Nesse tempo também se inclui a atualização da base cartográfica, pois, as plantas cadastrais do MSP são de 1974. A atualização dos usos e dos novos edifícios nos lotes pode ser feita com observação simples da calçada, portanto, sem um rigor geométrico. Rosa (1994) coloca que "O ideal é que se fizesse, anualmente, um novo recobrimento aerofotogramétrico e se procedesse à atualização através de restituição das áreas que sofreram alterações (...) A operação e manutenção do Cadastro deve se encarregar de continuamente ir acompanhando as alterações que vão ocorrendo em cada quadra fiscal através dos pro-

(2) Em municípios sem cartas cadastrais (1:2.000), pode-se fazer o levantamento de campo, apesar da menor precisão, na escala 1:10.000; porém, trabalhar com escalas menores na coleta de campo não é aconselhável. 
cessos de desmembramento de lotes, da construção de novas edificações ou de reformas nas existentes. Se tal procedimento não for adotado jamais a Prefeitura poderá pretender controlar eficientemente o uso e a ocupação do solo na cidade!"

\subsection{Coleta e análise dos dados}

O levantamento de como a cidade utiliza seu solo é de suma importância, pois está intimamente relacionado com as características físicas que a cidade apresenta. Vários autores relacionam a qualidade do ambiente com o tipo de utilização do solo, constatando-se que fatores ambientais (ar, água, solo e biosfera) de uma cidade são principalmente resultado da estrutura e uso dessas áreas. Segundo Sukopp e Werner (1991)," (...) os diferentes tipos de uso do solo se utilizam para caracterizar a área urbana e que, como se sabe, este fator exerce uma grande influência na qualidade dos biótopos urbanos (...)."

No trabalho de campo, os dados de uso de cada lote são anotados nas cópias das cartas cadastrais (escala 1:2.000), assinalando-se apenas os usos que interessam para a pesquisa, como por exemplo:

I - Uso exclusivamente residencial;

II - Uso não residencial e misto:

- poluidor: venda de veículos, acessórios e peças para autos, depósitos, transportadoras, serralheria, mecânica, posto de gasolina, indústria, estacionamentos ...

- não poluidor: bar, cinema, farmácia, padaria, escritório, banco, escola, templo, atendimento médico ...

III - Espaços Livres Públicos.
Como se pretende o cruzamento desses dados através de sobreposição de mapas, destacam-se os usos de interesse para a pesquisa de forma independente, mapeando-os em uma escala menor (1:10.000) formando-se, assim, uma "coleção de mapas" (Martinelli, 1991).

Acredita-se que, o controle dos usos na cidade, a organização da cidade em zonas de uso é, em parte, o que garantiria a qualidade ambiental em certos setores. Para Machado (1992), o fim primacial da divisão de uma cidade em zonas seria "O bem estar da população, principalmente no concernente à sua saúde, tranqüilidade, trabalho adequado, segurança, lazer e cultura dos valores especiais (...)".

Portanto, após a coleta dos dados de uso do solo através do trabalho de campo, pode-se elaborar uma carta, na escala 1:10.000, com a localização dos usos diferentes do residencial e dos espaços livres, pois considera-se que esses usos direta ou indiretamente diminuem a qualidade ambiental (Fig. 2).

A partir do levantamento de campo na escala 1:2.000 podem-se destacar também os principais usos causadores de poluição atmosférica, hídrica, visual e/ou sonora, ou seja, o "uso não residencial poluidor". Um levantamento qualitativo do tráfego permite um mapeamento das avenidas mais movimentadas. Do cruzamento desses dados chega-se ao zoneamento das fontes poluidoras do distrito na escala de 1:10.000 (Fig. 3).

Através do trabalho de campo, pode-se analisar também os Espaços Livres Públicos. O mapeamento dos espaços livres públicos é realizado a partir de levantamento de campo e a quantificação é feita com medidas nas cartas cadastrais escala 1:2.000.

O Sistema de Espaços Livres é o conjunto de espaços urbanos ao ar livre, destinados a todo 
tipo de utilização relacionada a pedestres (em oposição ao uso motorizado), descanso, passeio, prática de esporte, em geral, recreio e entretenimento em horas de ócio, como definiu Llardent (1982).

Os espaços livres públicos devem ser analisados segundo dois aspectos: o quantitativo e o qualitativo. $\mathrm{Na}$ análise quantitativa, considera-se o fato de existir ou não o espaço livre e também sua capacidade de suporte para o lazer da população adjacente a esse espaço. Como ainda não existem indicadores precisos de qualidade desses espaços, a análise qualitativa fica sujeita a interpretação do pesquisador, que deve descartar aqueles espaços que não apresentam condições saudáveis de uso pela população.

Geralmente não há, pelo menos nas grandes cidades brasileiras, um sistema de caminhos para passeios. As calçadas não cumprem esse papel, pois não estão desvinculadas do sistema viário, apresentando-se assim perigosas e sem nenhum atrativo. Sendo assim, não devem ser consideradas como espaços livres.

Agora, surge o problema de se determinar um índice ideal para a quantidade de espaços livres públicos por habitante. A partir de análises de índices de espaços livres urbanos sugeridos por vários autores, pode-se perceber que esses variam de aproximadamente 4 a $10 \mathrm{~m}^{2} /$ hab para áreas junto às habitações e unidades de vizinhança e de modo geral somando-se as faixas etárias e diferentes usos. Então, sem a existência na literatura de um índice amplamente aceito, pode-se determinar, dentro de pressupostos de não radicalização dos limites, que cada habitante teria, para usufruir do seu lazer, $5 \mathrm{~m}^{2}$ de espaço livre público. Para a possibilidade de espacialização desse índice, trabalha-se somente com a existência ou não do espaço livre público, excetuando-se aqueles espaços que não permitem um uso saudável pela população. Pretende-se espacializar a quantidade de pessoas que cada espaço livre público seria capaz de atender, utilizandose como critério o índice de $5 \mathrm{~m}^{2} /$ hab.

Então, com base no tamanho de cada espaço livre público e com os dados do número de moradores de cada setor censitário (IBGE), mapeia-se a capacidade de atendimento de cada espaço livre no distrito. Quanto mais gente morando ao redor do espaço livre e quanto menor for esse espaço, menor será sua área de influência. Chega-se, portanto, à delimitação das áreas onde a população não é servida por espaços livres públicos, ou seja, na carta do "déficit de espaços livres públicos" na escala 1:10.000 (Fig. 4).

Os gabaritos dos edifícios também são anotados na carta cadastral durante o trabalho de campo. Para a carta de Verticalidade das Edificações, os gabaritos acima de seis pavimentos são considerados como interferência negativa para a qualidade ambiental. As áreas onde a verticalização é mista não são consideradas no cruzamento (Fig. 5).

Com base nas características geomorfológicas da área de estudo, em croqui hipsométrico elaborado a partir dos pontos cotados das cartas cadastrais, em mapas antigos do sítio urbano nos quais pode ser visualizada a drenagem original e no trabalho de campo, elabora-se a carta de enchentes (Fig. 6).

Com uma carta dos setores censitários do distrito e os dados demográficos sobre o número de moradores, adquiridos no IBGE, calcula-se a área de cada setor censitário e constrói-se uma carta de densidade populacional na escala aproximada de 1:10.000.

Chegar a um índice ideal para a densidade populacional é muito difícil. Segundo Campos Filho (1972) "(...) não é nenhum absurdo a proposta de desenvolverem-se 'cenários' de dife- 
rentes formas urbanas, alternativas e estilos de vida relacionados com densidades em torno de 400 a 500 hab/ha". O padrão recomendável pela Associação Norte-americana de Saúde Pública é de $32 \mathrm{~m}^{2} / \mathrm{hab}(312,5 \mathrm{hab} / \mathrm{ha}$ ) (Tuan, 1977). Sob o aspecto da infra-estrutura urbana, Santos (1994) afirma que o razoável em todo mundo seria uma densidade de 100 a 120 hab/ha. Portanto, na carta de Densidade Populacional podem ser considerados como diminuidores da qualidade ambiental os valores acima de 400 hab/ha (Fig. 7).

A partir de foto aérea na escala 1:10.000, elabora-se a carta da distribuição dos "desertos florísticos", que são as áreas que se apresentam quase sem nenhuma mancha de verde (Fig. 8). Oke (1973), apud. Lombardo (1985), considera um índice de cobertura vegetal na faixa de $30 \%$ como sendo o recomendável para proporcionar um adequado balanço térmico em áreas urbanas, sendo que áreas com um índice de arborização inferior a $5 \%$ determinam características semelhantes às de um deserto.

\subsection{A carta de qualidade ambiental}

A partir das cartas de uso do solo (Fig. 2), poluição (Fig. 3), déficit de espaços livres públicos (Fig. 4), verticalidade das edificações (Fig. 5), enchente (fig. 6), densidade populacional (Fig. 7) e deserto florístico (Fig. 8), chega-se a uma carta síntese (Fig. 9).

A superposição desses sete atributos deve ser realizada em etapas, ou seja, sobrepõem-se duas cartas por vez. Por exemplo: do cruzamento da carta de pontos de enchentes com a carta de deserto florístico, elabora-se uma carta com a seguinte legenda: (1) Enchente e Deserto Florístico; (2) Enchente; (3) Deserto Florístico e (4) nenhum dos dois atributos. Essa carta é posteriormente sobreposta à carta de Poluição, originando uma segunda síntese parcial com a seguinte legenda: (1) Enchente, Deserto Florístico e Poluição; (2) Enchente e Deserto Florístico; (3) Enchente e Poluição; (4) Deserto Florístico e Poluição; (5) Enchente; (6) Deserto Florístico; (7) Poluição e (8) nenhum dos três atributos. Esse procedimento se repete até o último atributo, concluindo-se, assim, a síntese final, ou seja, a carta de Qualidade Ambiental.

Não há a intenção, no momento, de aplicar valores quantitativos aos atributos, portanto, a carta de qualidade ambiental apresenta uma valoração qualitativa, que deve ser analisada de forma relativa, ou seja, a área que apresenta todos os sete atributos tem uma pior qualidade ambiental em relação à que apresenta somente seis atributos, e assim por diante. Além disso, todos os sete atributos são considerados como tendo o mesmo peso na capacidade de diminuir a qualidade ambiental. Também, não se considera, nesse procedimento, se a enchente é mais prejudicial do que a poluição, mas apenas que qualquer um dos dois atributos diminui a qualidade ambiental das áreas onde ocorrem e, portanto, devem ser considerados no planejamento.

\section{CONCLUSÃO}

É muito comum, nas leis brasileiras, a existência de termos sem nenhuma qualificação humanizado, sadio, ecologicamente equilibrado, potencial, limites - que não conseguem definir em atos concretos os parâmetros pelos quais o cidadão pode se orientar, entretanto existe uma intenção de, junto à sociedade, estabelecer estes critérios, como coloca o artigo 181 da Lei Orgânica do MSP (PMSP, 1990): “O Município, mediante lei, organizará, assegurada a participação da sociedade, sistema de 
administração da qualidade ambiental (...): estabelecimento de normas, critérios e padrões para a administração da qualidade ambiental".

Para que isso seja possível são necessários investimentos em pesquisas que possam fornecer os indicadores de qualidade ambiental e capacidade de suporte dos ecossistemas urbanos.
Esta proposta metodológica poderia fazer parte de um conjunto de mecanismos de um sistema de administração da qualidade ambiental urbana e sugestões de planejamento, como a da escolha de áreas adensáveis, deveriam ser derivadas desse diagnóstico ambiental.

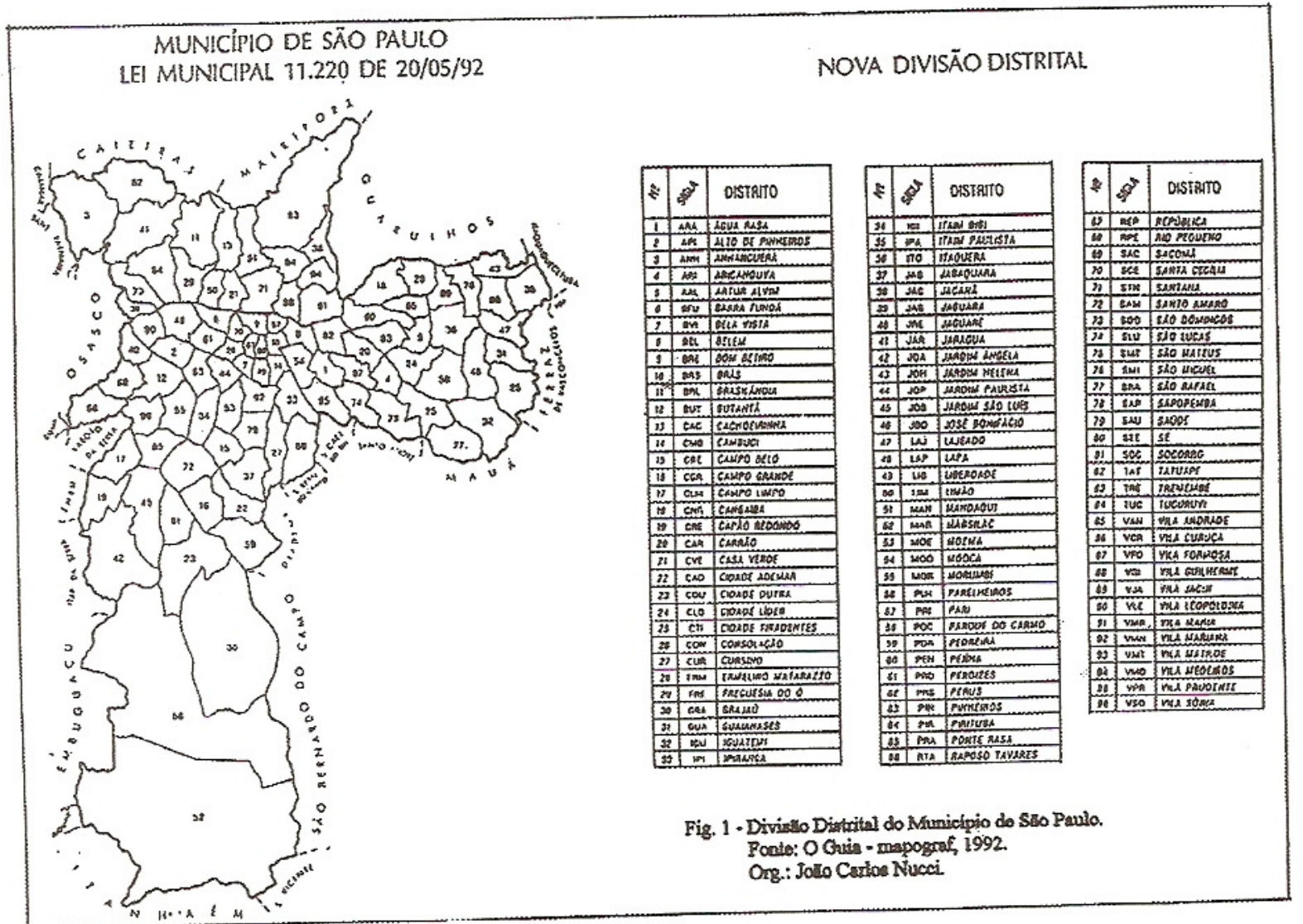



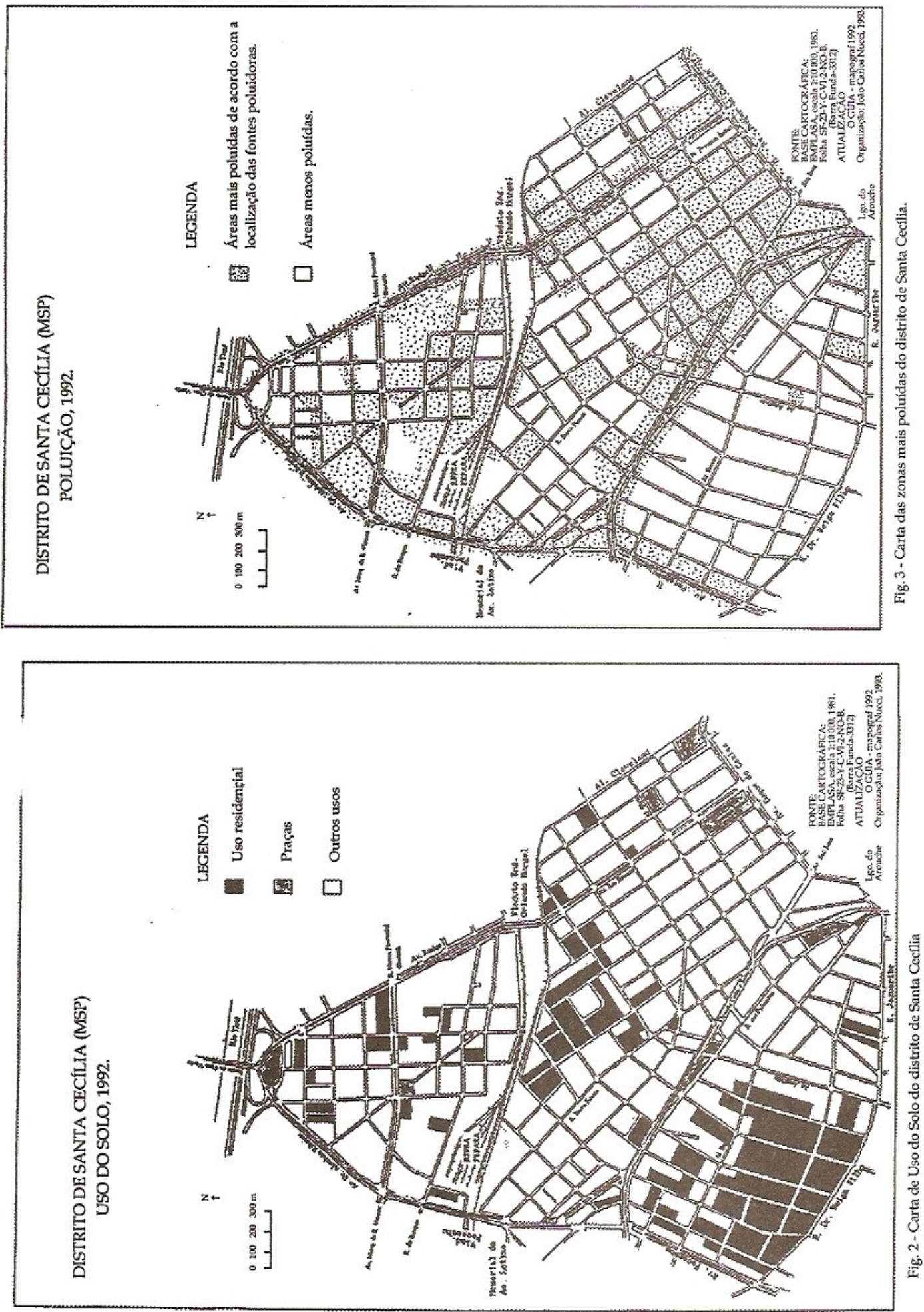

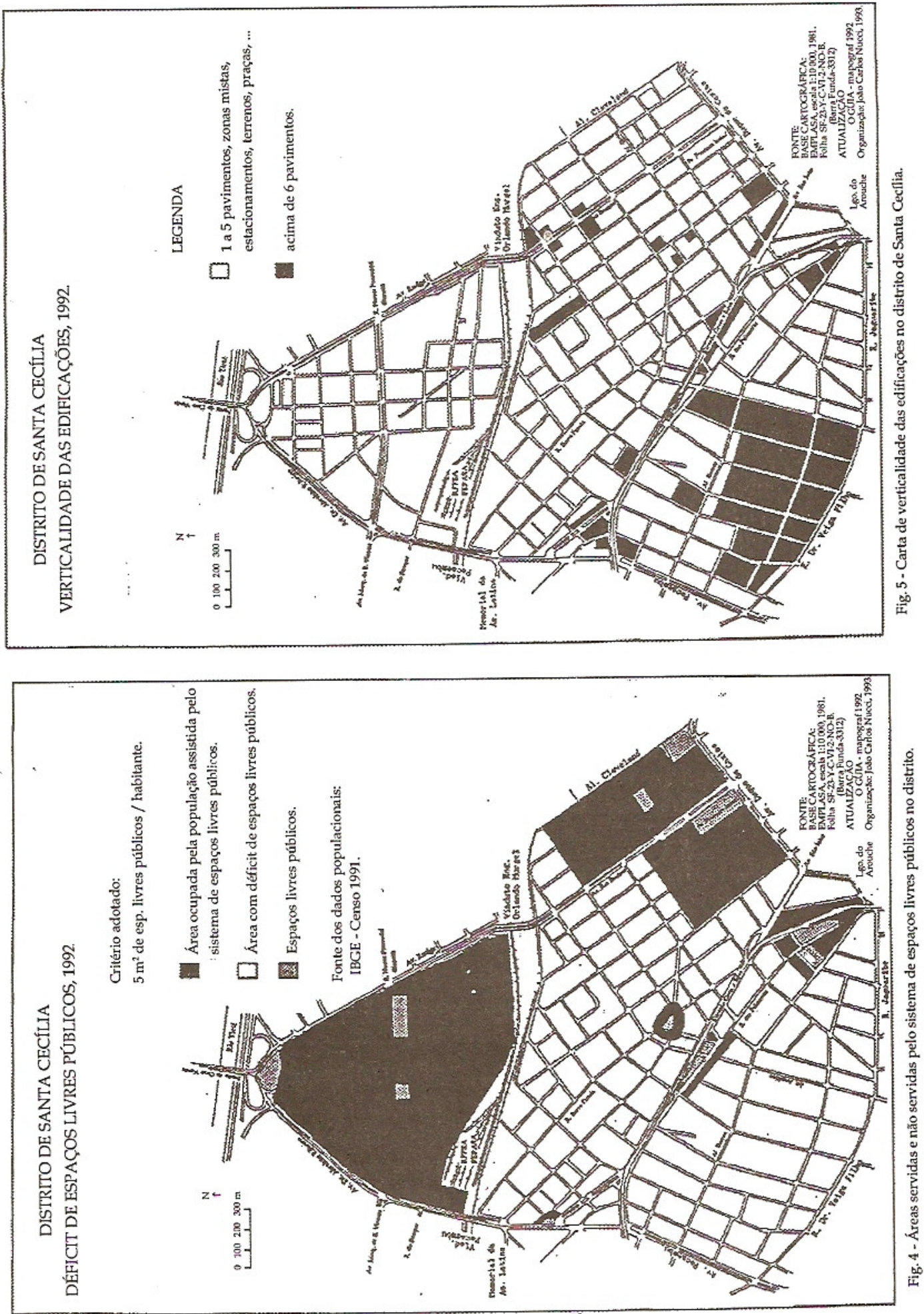

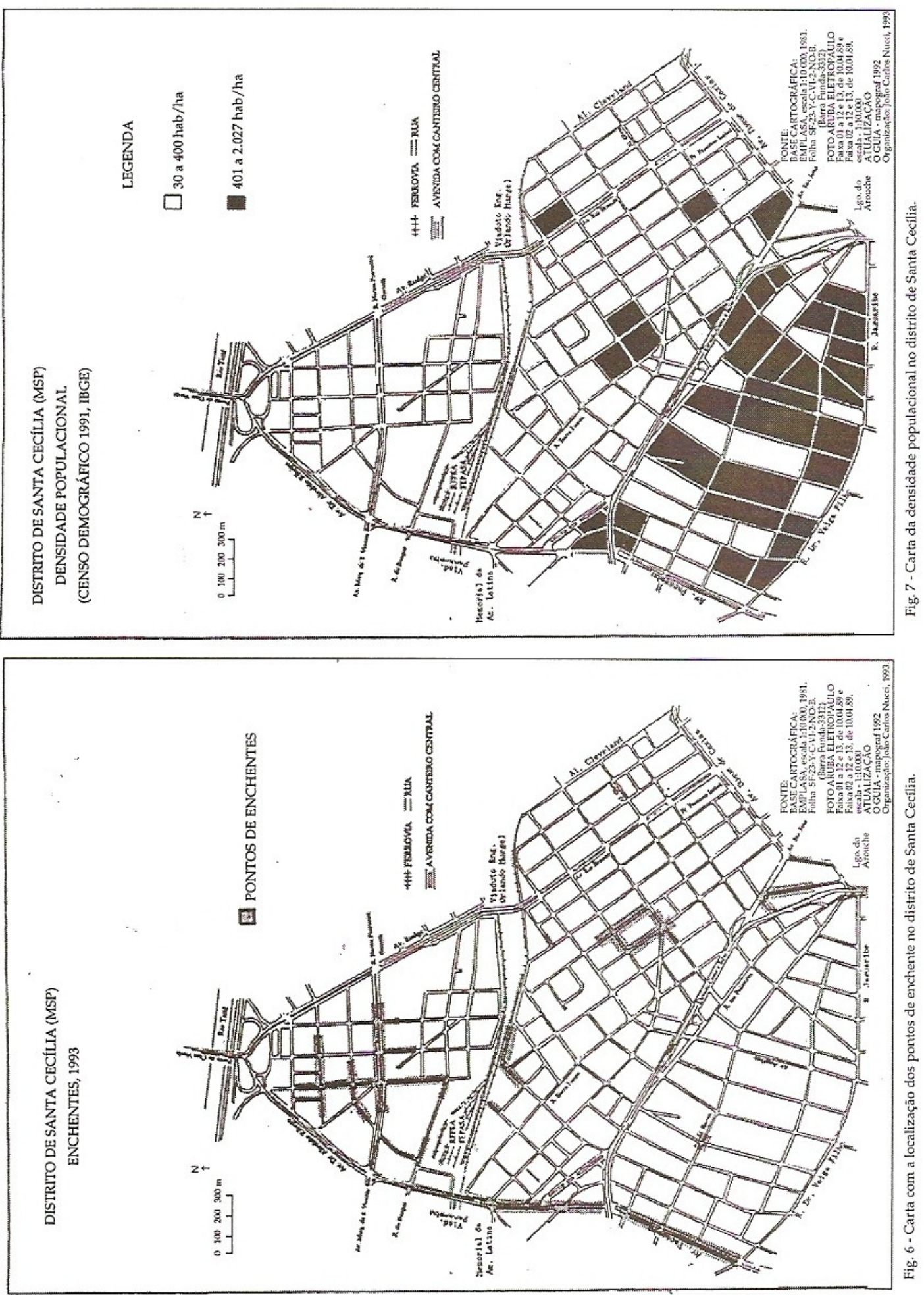


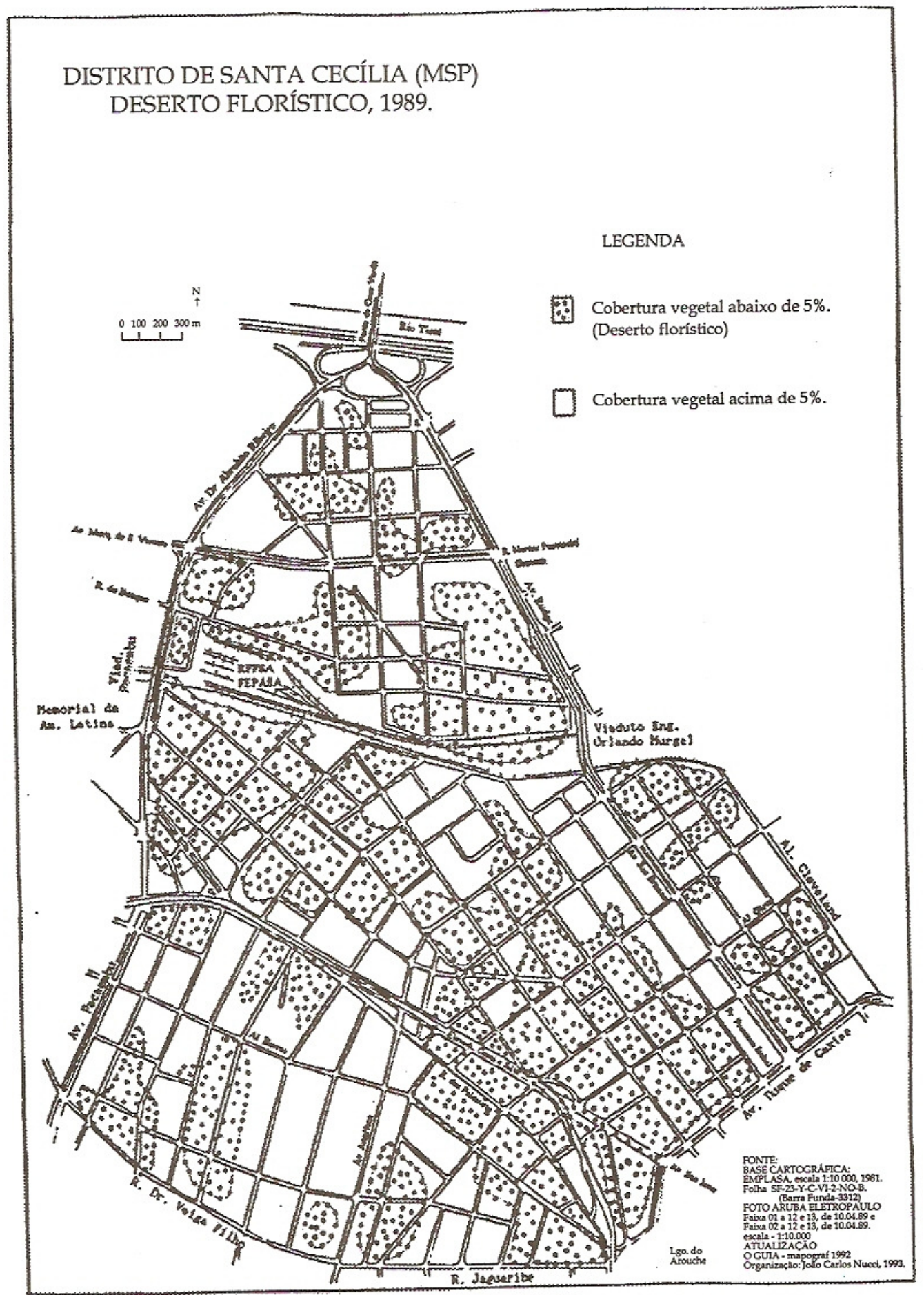

Fig. 8 - Carta com a localização dos "desertos floristicos" no distrito de Santa Cecllia. 


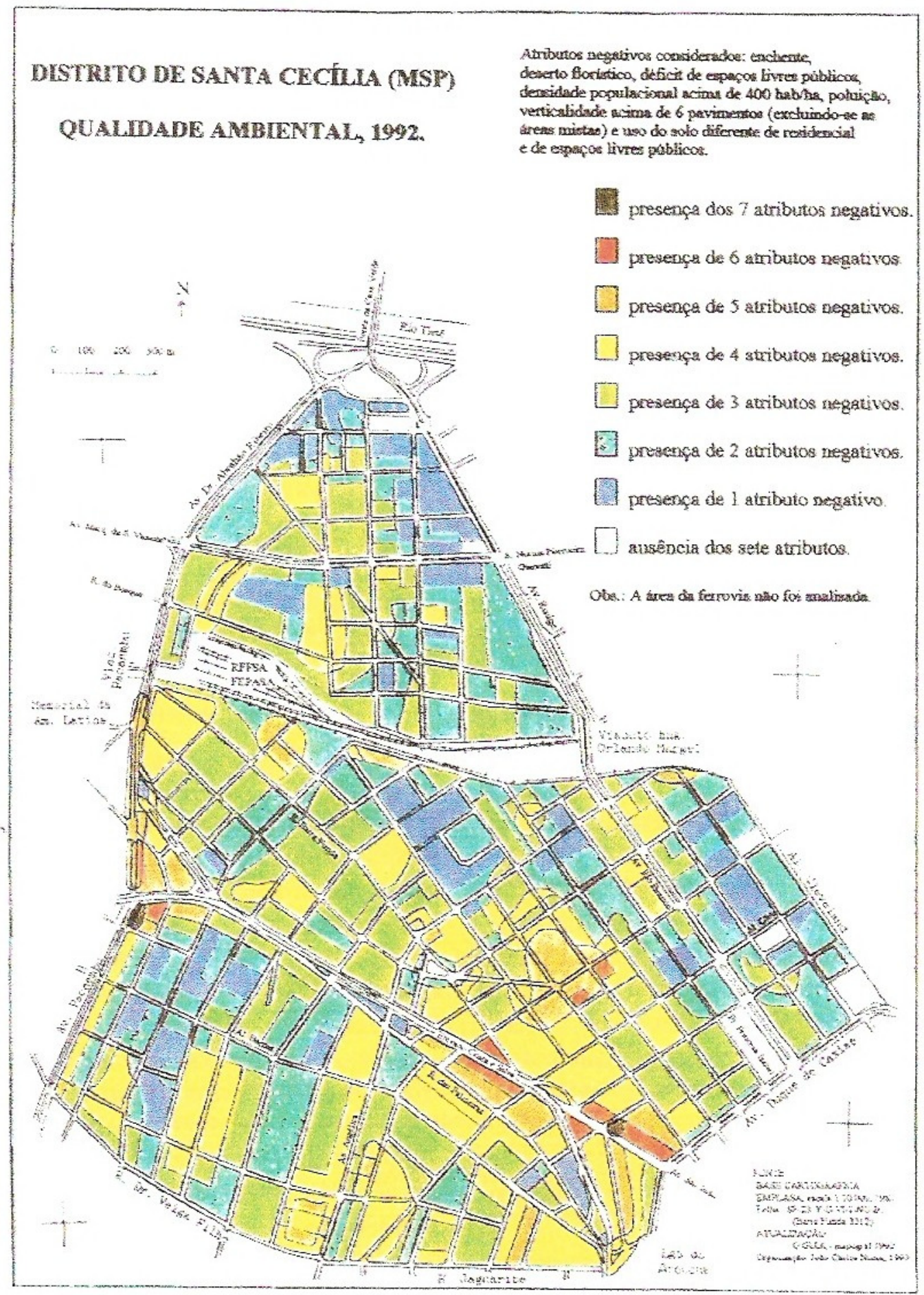

Fig. 9 - Carta da Qualidade Ambiental do distrito de Santa Cecilia. 


\title{
5. BIBLIOGRAFIA
}

BERTIN, J. A generalização cartográfica. Bulletin du Comité Français de Cartographie, (36):62-65, 1968. Trad. Marcello Martinelli.

CAMPOS FILHO, C. M. Corredor metropolitano como estrutura urbana aberta para a Grande São Paulo. Tese de Doutoramento. FAU-USP, 1972.

CAVALHEIRO, F. \& DEL PICCHIA, P. C. D. Áreas verdes: conceitos, objetivos e diretrizes para o planejamento. In: ENCONTRO NACIONALSOBRE ARBORIZAÇÃO URBANA, 4 Vitória-ES, de 13 a 18 de set/92, Anais I e II, 1992, p. 29-38.

Cartografia ambiental: uma cartografia diferente? Revista do Dept. de Geografia, (7):61-80, 1994.

DOUGLAS, I. The urban environment. London, Edward Arnold (Publishers) Ltda, 1983. 229 p.

HIEMSTEDT, H. e GUSTEDT, E. Landschaftsplanung als Instrument umfassender Umweltvorsoge (Conferência Internacional), 1990.

LLARDENT, L. R. A. Zonas verdes y espacios libres en la ciudad. Madrid, Inst. de Estudios deAdministración Local, 1982. $538 \mathrm{p}$.

LEFEBVRE, H. O direito à cidade. 1969.

LOMBARDO, M. A. Itha de calor nas metrópoles. O exemplo de São Paulo. São Paulo, HUCITEC, 1985. 244 p.

MACHADO, P.A. L. Direito ambiental brasileiro. Ed. Malheias, 1992.

MARCUS, M.G. \& DETWYLER, T.R. Urbanization and environment. Bermont/Cal., Duxburg Press, 1972. 286 p.

MARTINELLI, M. Curso de cartografia temática. São Paulo, Contexto, 1991, $180 \mathrm{p}$
Cartografia ambiental: uma cartografia diferente? Revista do Dept. de Geografia, (7):61-80, 1994.

MONTEIRO, C.A.de F. Qualidade ambiental - Recôncavo e Regiöes limítrofes. Salvador, Centro de Estatísticas e Informações, 1987, 48 p. e 3 cartas.

NUCCI, J. C. \& CAVALHEIRO, F. Escala de proporção espacial e mapeamento do uso do solo no ambiente urbano. In: VIII SEMINÁRIO REGIONAL DE ECOLOGIA. São Carlos/SP, de 12 a 15 de Março de 1996 (no prelo).

NUCCI, J. C. Qualidade Ambiental e Adensamento: um estudo de Planejamento da Paisagem do distrito de Santa Cecília (MSP). USP-FFLCH-GEOGR. Tese de doutorado, São Paulo, 1996. 229 p.

PMSP. Lei Orgânica do Município de São Paulo de 1990.

PMSP. Lei n. 11.220 de 20.05.92: Nova divisão distrital para o MSP.

ROCHA, A. A. Do lendário Anhembi ao poluido Tietê. São Pau1o, EDUSP, 1991. 75 p.

ROSA, F. S. Viabilidade da atualização cartográfica. Rev. do Dept. de Geo USP-FFLCH, n. 8, 1994.

SANTOS, R. C. B. dos. Rochdale e Alphaville: formas diferenciadas de apropriação e ocupação da terra na metrópole paulistana. São Paulo. Tese de doutoramento. FFLCHUSP, 1994. 277 p.

SUKOPP, H. \& WERNER, P. Naturaleza en las ciudades. Madrid, 1991.

TUAN, Y. Espaço e lugar. DIFEL, 1977. 250 p.

\begin{abstract}
Based on "Landscape Planning", a specific methodology is proposed for the assessment of the quality of urban environment, and using the district of Santa Cecilia (MSP), as an example. Land use, pollution, open spaces, verticality of buildings, flood, population density and tree-canopy coverage are the studied parameters and spaced out on scales that range from 1:2.000 to 1:10.000. Systemic analysis of these parameters provides the Environmental Quality chart.
\end{abstract}

